\title{
ESTUDO COMPARATIVO DA SENSIBILIDADE E ESPECIFIDADE DOS TESTES ANTÍGENO ACIDIFICADO TAMPONADO (AAT) E 2-MERCAPTOETANOL NO DIAGNÓSTICO DA BRUCELOSE BOVINA
}

\author{
Comparative Study on the Sensitivity and Specificity of the Buffered Acidified \\ Antigen and 2-Mercaptoethanol Tests in the Diagnostic of Bovine Brucellosis
}

Iuri Coelho Greve

Graduando de Medicina Veterinária da UNIME, Lauro de Freitas - BA.

e-mail: iurigreve@yahoo.com.br

Juliano Zerbinati

Graduando de Medicina Veterinária da UNIME, Lauro de Freitas - BA.

e-mail: julianozerbinati@hotmail.com

Renata Franco Leal

Graduanda de Medicina Veterinária da UNIME, Salvador - BA. e-mail: renata_115@hotmail.com

Luciane Mari Prado Vasconcelos de Amorim

Graduando de Medicina Veterinária da UNIME, Salvador - BA.

e-mail: iurigreve@yahoo.com.br

Diógenis Lima da Silva

Auxiliar de Saúde do Laboratório de Doenças Infecciosas da UNIME/LADI, Salvador - BA.

e-mail: diogenisls@hotmail.com

Eugênia Marcia de Deus Oliveira

Prof. da UFBA, Salvador - BA.

e-mail: iurigreve@yahoo.com.br

\section{Renato Carminati}

Médico Veterinário, M. Sc., Prof. da UNIME, Lauro de Freitas - BA.

e-mail: rcarminat@gmail.com

Robson Bahia Cerqueira

Médico Veterinário, M. Sc., Prof. da UNIME, Lauro de Freitas - BA.

e-mail: robsonba@gmail.com 


\title{
Resumo
}

A brucelose é uma enfermidade que acomete os animais e o homem e requer uma atenção especial, pois acarreta impactos à saúde pública e prejuízos econômicos. O combate dessa enfermidade é necessário por se tratar de uma importante zoonose. O diagnóstico eficaz é essencial para impedir a disseminação e diminuir as fontes de infecção. Este trabalho teve como objetivo avaliar e comparar os testes de Soroaglutinação Lenta (SAL), 2-Mercaptoetanol (2-ME) e o Antígeno Acidificado Tamponado (AAT) quanto à sua sensibilidade e à especificidade, relacionado ao sorodiagnóstico da brucelose bovina. Desse modo, foram selecionadas 70 amostras de soro bovino, sendo que 50 foram reagentes e 20 não-reagentes ao AAT. Todas as amostras foram submetidas aos testes do SAL e 2ME. Os animais foram procedentes de fazendas de produção leiteira, fêmeas da raça girolando, com idades variáveis entre 2 a 5 anos, vacinadas na idade tradicional. Os testes tiveram um bom desempenho, sendo que o 2-ME teve maior especificidade em relação ao SAL e AAT. O SAL teve uma sensibilidade maior que o 2-ME e especificidade maior que o AAT. O AAT demonstrou ser um teste mais sensível e rápido, quando comparado aos outros dois. Conclui-se que o 2-ME é um ótimo teste confirmatório e o AAT é um bom teste de triagem.

Palavras-chave: Brucelose bovina; Sorodiagnóstico; Antígeno acidificado tamponado; 2Mercaptoetanol; Soroaglutinação lenta.

\begin{abstract}
Brucellosis is an infirmity that deserves a special attention because of the fact that by affecting animals and men, it brings on impacts towards public health as well as economical harm. By being a very important zoonosis, it is essential the control and the attack of such infections disease in order to hinder its dissemination and diminish its sources of infection. The aim of the present research has been to compare and evaluate the slow serumagglutination $(S A L)$, 2-mercaptoethanoI (2-ME), and buffered acidified antigen (AAT) tests in regard to their sensitivity and specificity properties towards the bovine brucellosis serum diagnostic. For this research, 70 samples of serum from 2 to 5 years old 'girolando' female bovines from milk farmers, all of them vaccinated at the traditional age, were used. From them, a total 50 samples were reagents and 20 non reagents towards AAT. All samples were subjected to the SAL and 2-ME tests. According to the results, the 2-ME displayed more specificity in regard to SAL and ATT, the SAL showing more sensitivity than the 2-ME and more specificity than the AAT. According to the results, the AAT test showed to be more sensitive and rapid when compared to the other two tests. On the other hand, the 2-ME is an excellent confirmatory test and the ATT a good selection test.
\end{abstract}

Keywords: Bovine brucellosis; Serumdiagnostic; Buffered Acidified Antigen; 2-Mercaptoethanol; Slow Serum Agglutination.

\section{INTRODUÇÃO}

A brucelose é uma doença infecto-contagiosa do grupo das zoonoses que acomete os animais domésticos, principalmente bovinos, cabras e ovinos, podendo ser transmitida ao homem. As bactérias podem ser veiculadas por ingestão de leite e produtos lácteos crus ou deficientemente cozidos, contato, inalação e inoculação acidental (SALGADO, 1995). A Brucella abortus, na maioria dos casos, invade o organismo pelo sistema digestivo, multiplica-se nos linfonodos e na orofaringe, produzindo bacteremia (MOLNAR et al., 1997). O controle da brucelose bovina vem passando por dificuldades, devido à precariedade de recursos viáveis para uma possível erradicação. Do ponto de vista técnico, deve-se 
salientar que a brucelose bovina atinge diferentes áreas e por esse motivo, em cada região, existe uma prevalência diferenciada, necessitando de programas para o controle da enfermidade (ACYPRESTE et al., 2002). As principais provas utilizadas no sorodiagnóstico da brucelose bovina tem sido a soroaglutinação lenta em tubos (SAT), rápida em tubos (SAR), antígeno acidificado tamponado (AAT), 2- mercaptoetanol (2-ME), reação de fixação de complemento (FC) e sêmen plasma aglutinação (SPA) (RADOSTITS; GAY; BLOOD, 2000). Este trabalho teve como objetivo avaliar comparativamente a especificidade e a sensibilidade das provas sorológicas do antígeno acidificado tamponado, do 2-mercaptoetanol e da soroaglutinação lenta em amostras de soro bovino.

\section{MATERIAIS E MÉTODOS}

As amostras de soro foram fornecidas gentilmente pelo Clinilab (Clínica e Laboratório de Reprodução) e Laboratório de Zoonoses da Universidade Federal da Bahia. Foram utilizadas 70 amostras de soros bovinos, raça girolando, sendo 50 de soros reagentes ao antígeno acidificado tamponado (AAT) e 20 não-reagentes. Cada alíquota continha aproximadamente 1,5 $\mathrm{ml}$. Os animais foram provenientes de fazendas com produção leiteira, em que todas eram fêmeas vacinadas na idade entre 3 a 8 meses e com idade entre 24 a 60 meses no momento da coleta.

\section{Prova do antígeno acificado tamponado (AAT)}

O antígeno, produzido no Instituto de Tecnologia do Paraná (TECPAR), foi adquirido pelo órgão de Defesa (ADAB). A linhagem utilizada foi a Brucella abortus 1119-3, na concentração celular de 4\%, inativada pelo calor e corado pela Rosa de Bengala. Partida: 002/05 e data de fabricação: Mar/05. O protocolo foi realizado conforme recomendação do Programa de Controle da Brucelose e Tuberculose Bovinas organizado pelo Ministério da Agricultura. Os soros e o antígeno foram retirados da geladeira e freezer, respectivamente, e colocados à temperatura ambiente por aproximadamente 30 minutos. Em seguida, as amostras de soro foram organizadas em galeria, identificados em uma ficha de controle interno do LADI, homogeneizado e, com uma micropipeta, retirou-se de cada amostra $30 \mu$ de soro, colocado, com um ângulo de $45^{\circ}$, em placa de vidro. O antígeno foi colocado ao lado, na mesma quantidade, sem que tivesse contato com o soro. Após homogeneização e com a ajuda de um bastão, foram realizados movimentos circulares, 30 vezes aproximadamente por minuto, durante 4 minutos. A leitura foi feita com o auxílio de caixa de fundo escuro e a identificação da reação foi observada pela presença ou não de grumos.

\section{Prova do 2-Mercaptoetanol}

O antígeno utilizado foi o mesmo que se utiliza para a prova de soroaglutinação lenta, com concentração de massa bacteriana de 4,5\%, sem corante, padronizado a partir da cepa 1119-3 de Brucella abortus, inativada pelo calor, produzido pelo Instituto de Tecnologia do PARANÁ (TECPAR). Partida: 001/06 e data de fabricação: Fev/06. O protocolo foi realizado conforme recomendação do Programa de Controle da Brucelose e Tuberculose Bovinas organizado pelo Ministério da Agricultura. Os soros reagentes na prova do AAT foram identificados, homogeneizados e submetidos à prova do 2-ME. Com a pipeta de Bang, os soros foram colocados em tubos identificados com as respectivas numerações, onde cada amostra possuía 4 tubos, com distribuição de $0,08 \mathrm{ml}, 0,04 \mathrm{ml}, 0,02 \mathrm{ml}, 0,01 \mathrm{ml}$ do soro, respectivamente.

O 2-ME foi diluído em solução salina a uma concentração de $0,78 \%$ e pipetado $1 \mathrm{ml}$ em cada tubo, contando 30 minutos de descanso e, em seguida, foi adicionado $1 \mathrm{ml}$ do antígeno diluído em solução salina a $2 \%$. Após 48 horas, foi realizada a leitura, com o teste controle positivo e negativo, e analisadas as precipitações com formação de grumos e classificados como reagentes de acordo com as diluições 1:25, 1:50, 1:100, 1:200. 


\section{Prova da soroaglutinação lenta (SAL)}

O antígeno utilizado apresenta concentração de massa bacteriana de 4,5\%, sem corante, padronizado a partir da cepa 119-3 de Brucella abortus, inativado pelo calor, produzido pelo Instituto de Tecnologia do Paraná (TECPAR). Partida: 001/06 e data de fabricação: Fev/06.

O protocolo foi realizado conforme recomendação do Programa de Controle da Brucelose e Tuberculose Bovinas organizado pelo Ministério da Agricultura. Os soros reagentes na prova do AAT foram identificados, homogeneizados e submetidos à prova do SAL. Com a pipeta de Bang, os soros foram colocados em tubos identificados com as respectivas numerações, onde cada amostra possuía 4 tubos, com distribuição de $0,08 \mathrm{ml}, 0,04 \mathrm{ml}, 0,02 \mathrm{ml}, 0,01 \mathrm{ml}$, respectivamente. $\mathrm{O}$ fenol foi diluído em soro fisiológico a 0,5\% e o antígeno foi diluído a 1\% na solução salina fenicada. Em seguida, foram transferidos $2 \mathrm{ml}$ para cada tubo. Após 48 horas, foi realizada a leitura, com o teste controle positivo e negativo, e analisadas as precipitações com formação de grumos e classificados como reagentes de acordo com as diluições 1:25, 1:50, 1:100, 1:200.

\section{Estudo estatístico}

As determinações da sensibilidade e da especificidade relativas das provas de AAT, SAL e 2ME foram calculadas entre si, utilizando a tabela 2x2. Os cálculos correspondem à publicação de Madruga; Araújo; Soares (2001), conforme cálculos abaixo:

\begin{tabular}{|c|c|c|}
\hline & & + \\
\hline Resultado do & + & A \\
\hline Teste estudado & - & $\mathrm{B}$ \\
\hline Sensibilidade $=$ & $\frac{A}{A+B} 100$ & \\
\hline Especificidade $=$ & $\frac{D}{D+C} 100$ & \\
\hline
\end{tabular}

\section{RESULTADOS}

Das 70 amostras de soro submetidas à prova do Antígeno Acidificado Tamponado (AAT), 50 apresentaram reação ao teste (FIGURA 1). É importante atentar que as 70 amostras foram submetidas aos testes SAL e 2-ME e o resultado foi obtido pela leitura da tabela de referência para animais vacinados na idade tradicional e acima de 24 meses, seguindo preconização do Programa Nacional de Controle e Erradicação da Brucelose. 


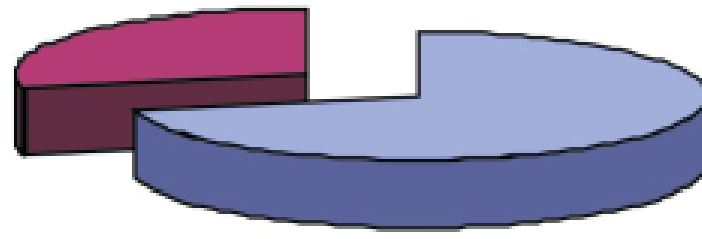

\section{$\square$ Reagente \\ Não reagente}

FIGURA 1 - Percentagem de soro bovino submetidos ao teste do AAT

Figure 1 - Percentage of bovines samples at ATT test

Das 70 amostras submetidas aos testes de soroaglutinação lenta (SAL) e 2-Mercaptoetanol (2-ME), 4 apresentaram titulação de 1:25 no SAL, sendo uma incompleta, 6 apresentaram titulação de 1:50, 8 titulação de 1:100 e, dessas, 5 apresentaram reações incompletas e 32 resultados concordantes com relação ao AAT. As amostras foram submetidas ao 2-Mercaptoetanol, tendo 5 amostras com titulação de 1:25, 10 com titulação de 1:50, sendo que 2 incompleta, 1 com titulação de 1:100. Observouse também que 27 amostras apresentaram reação positiva para as titulação de 1:200, onde 3 mostraram reação incompleta e 7 não reagiram ao 2-ME.

TABELA 1 - Sensibilidade e especificidade relativas da prova do antígeno acidificado tamponado calculadas com base nos resultados da soroaglutinação lenta

Table 1 - Sensibility and specificity towards the test of the buffered acidified antigen calculated in regard to the slow serum agglutination results

\begin{tabular}{lccc}
\hline AAT & Reagente & Não Reagente & TOTAL \\
\hline Reagente & 49 & 1 & 50 \\
Nåo Reagente & 0 & 20 & 20 \\
\hline TOTAL & 49 & 21 & 70 \\
\hline
\end{tabular}

Sensibilidade: 100\%; Especificidade: 95\%

TABELA 2 - Sensibilidade e especificidade relativas da prova do antígeno acidificado tamponado calculadas com base nos resultados do 2-mercaptoetanol

Table 2 - Sensibility and specificity towards the test of the buffered acidified antigen calculated in regard to 2-mercaptoethanol results

\begin{tabular}{lccc}
\hline AAT & Reagente & Nåo Reagente & TOTAL \\
\hline Reagente & 44 & 6 & 50 \\
Näo Reagente & 0 & 20 & 20 \\
\hline TOTAL & 44 & 26 & 70 \\
\hline
\end{tabular}

Sensibilidade: 100\%; Especificidade: 77\% 
TABELA 3 - Sensibilidade e especificidade relativas da prova da soroaglutinação lenta calculadas com base nos resultados do 2-Mercaptoetanol

Table 3 - Sensibility and specificity of the slow serum agglutination test calculated in regard to the results from 2-Mercaptoethanol

\begin{tabular}{lccc}
\hline SAL & Reagente & Nä̀ Reagente & TOTAL \\
\hline Reagente & 44 & 5 & 49 \\
Näo Reagente & 0 & 21 & 21 \\
\hline TOTAL & 44 & 26 & 70 \\
\hline
\end{tabular}

Sensibilidade: 100\%; Especificidade: 80\%

TABELA 4 - Sensibilidade e especificidade relativas da prova da soroaglutinação lenta calculadas com base nos resultados do antígeno acidificado tamponado

Table 4 - Sensibility and specificity of the slow serum agglutination test calculated in regard to buffered acidified results

\begin{tabular}{lccc}
\hline SAL & Reagente & Não Reagente & TOYTAL \\
\hline Reagente & 49 & 0 & 49 \\
Nåo Reagente & 1 & 20 & 21 \\
\hline TOTAL & 50 & 20 & 70 \\
\hline
\end{tabular}

Sensibilidade: 98\%; Especificidade: 100\%

TABELA 5 - Sensibilidade e especificidade relativas da prova do 2-mercaptoetanol calculadas com base nos resultados do antígeno acidificado tamponado

Table 5 - Sensibility and specificity of the 2-Mercaptoethanol test calculated in regard to the buffered acidified antigen results

\begin{tabular}{lccc}
\hline 2-ME & Reagente & Não Reagente & TOTAL \\
\hline Reagente & 44 & 0 & 44 \\
Não Reagente & 6 & 20 & 26 \\
\hline TOTAL & 50 & 20 & 70 \\
\hline
\end{tabular}

Sensibilidade: 88\%; Especificidade: 100\%

TABELA 6 - Sensibilidade e especificidade relativas da prova do 2-mercaptoetanol calculadas com base nos resultados da soroaglutinação lenta

Table 6 - Sensibility and specificity of the 2-Mercaptoethanol test calculated in regard to the slow serum agglutination results

\begin{tabular}{lccc}
\hline 2-ME & Reagente & Nìo Reagente & TOTAL \\
\hline Reagente & 44 & 0 & 44 \\
Nào Reagente & 5 & 21 & 26 \\
\hline TOTAL & 49 & 21 & 70 \\
\hline
\end{tabular}

Sensibilidade: 89\%; Especificidade: 100\% 
Estudo comparativo da sensibilidade e especifidade dos testes antígeno acidificado

tamponado (AAT) e 2-mercaptoetanol no diagnóstico da brucelose bovina

\section{DISCUSSÃO}

O Programa de controle da brucelose no Brasil estabeleceu regras de combate da doença preconizando a vacinação de bezerras de 3 a 8 meses e o uso de técnicas de diagnóstico como AAT, SAL e 2-ME como provas sorológicas oficiais. Contudo, o emprego de técnicas de imunodiagnóstico em programas de controle da doença permite reduzir o número de animais doentes, possibilitando a detecção de casos crônicos, eliminação de suspeitos e aumento da produtividade. Os resultados obtidos no presente experimento possibilitam o entendimento das diferenças de sensibilidade e especificidade entre os testes, contribuindo com informações para o controle da doença nos rebanhos.

Jardim et al. (2006) preconizam que as técnicas de diagnóstico para brucelose usadas em rebanho conhecidamente não-reagente para a enfermidade apresentaram uma alta taxa de resultados reagentes que não pode ser explicada pela prevalência da doença na população estudada, assumindo-se que os resultados reagentes encontrados representam um reflexo da falta de especificidade dos métodos utilizados para identificação de reação vacinal.

Megid et al. (2000) demonstraram a ocorrência de falso-positivo e falso-negativo utilizando, como diagnóstico, a prova de soroaglutinação rápida como teste de triagem, o que possibilitou a permanência dos animais reagentes e a eliminação do falso-positivo. Desse modo, foi concluído que devem ser encaminhadas para retestes específicos as amostras suspeitas e positivas e sugere como teste de triagem o AAT em substituição à SAR, por ser mais sensível, específico, prático e de baixo custo. Os resultados do presente experimento conferem com os obtidos pelo referido autor, uma vez que o antígeno acidificado tamponado, além de ser teste de triagem de baixo custo e rápido, apresentou sensibilidade de 100\% .

Kuroda et al. (2004), realizando um estudo comparativo dos resultados das técnicas de SAT, 2-ME e FC, relataram que 45 amostras de soro sanguíneo de bovinos foram positivas no AAT, 50 amostras reagentes no SAT, 29 reagente no 2-ME, 28 reagente e 3 suspeitas no FC. Assim, concluíram que o AAT, como método de triagem, apresentou concordância quando comparado com o 2-ME e FC. Já com SAT houve moderada concordância com a prova de FC. No presente experimento, os resultados obtidos demonstraram concordância significativa entre o teste de AAT e 2-ME, que apresentaram sensibilidade de $100 \%$ e $88 \%$, respectivamente, demonstrando semelhança com os dados obtidos no trabalho citado (PAULIM et al., 2002).

Mathias et al. (2001) analisaram a evolução de títulos sorológicos em bezerras vacinadas aos 18 meses, por meio da soroaglutinação em placa, sendo que, antes da vacinação, oito animais apresentaram titulação de 1:25. Após 45 dias da vacinação, foi detectada titulação de 1:100 em todas as bezerras. Após 12 meses, $1,85 \%$ do rebanho apresentou a mesma titulação e após 18 meses apenas $0,92 \%$. No teste AAT, antes da vacinação, todas as bezerras apresentaram-se não-reagentes ao teste, mas após 45 dias todas apresentaram-se reagentes. Depois de 6 meses da vacinação, 19,44\% do rebanho foi diagnosticado reagente, com 12 meses $10,19 \%$ e com 18 meses 8,33\%.

Jardim et al. (2006) avaliaram a freqüência de anticorpos em animais adultos vacinados com dose reduzida da B19, e após 3 meses 46,77\% dos animais apresentaram-se como reagente à prova de $\mathrm{FC}$, $67,74 \%$ para o AAT, 87,09\% para SAL e 2-ME e 100\% para o ELISA ID, concluindo que, mesmo com a dose reduzida, há interferência no sorodiagnóstico e que nenhuma técnica apresentou especificidade para bovinos vacinados em idade adulta, no período de 3 meses pós-vacinal, com a vacina B19 reduzida. Percebe-se que apesar dos testes utilizados neste experimento apresentarem elevada sensibilidade, essas não diferem fêmeas vacinadas de fêmeas naturalmente infectadas.

Ribeiro et al. (1997), baseados nos resultados do experimento, com o intuito de verificar o perfil sorológico anti-Brucella abortus em bezerras vacinadas de 3 a 8 meses com a vacina B19, relataram que todas as bezerras apresentaram resultados negativos, após 10 meses da vacinação, nas provas do 2ME, AAT, SAT e SAR, sugerindo que é possível utilizar essas provas mais precocemente do que a recomendação feita pelo MAPA.

Acypreste et al. (2002) demonstraram que, de 106 amostras de leite colhidas em 45 propriedades na bacia leiteira de Goiânia e submetidas à prova do anel do leite, 6 foram reagentes (5,66\%), 14 suspeitas $(13,21 \%)$ e 86 não-reagentes $(81,13 \%)$. Com o teste AAT foram coletadas 870 amostras de soro sangüíneo, 
tendo como reagentes $15(1,72 \%)$ e $855(98,28)$ não reagentes. Esses dados mostraram que houve concordância entre os testes, onde 5 das 45 propriedades apresentaram rebanhos reagentes na prova do anel do leite e 8 na prova do AAT. Fato semelhante foi observado no presente experimento, que mostrou a elevada sensibilidade apresentada pelo rosa de bengala.

Aguiar et al. (2001), em um experimento como provas sorológicas do diagnóstico da brucelose bovina, verificaram a SAR, detectando 58 reagentes, sendo 29 com titulação de 1:25, 21 com titulação de 1:50 e 8 com titulação de 1:100, enquanto que com o 2-ME e AAT nenhum animal foi detectado. Esses resultados são concordantes com os obtidos neste experimento, onde se demonstra a boa sensibilidade do SAL, que varia 98 a 100\%, identificando com clareza os animais expostos ao patógeno.

Ortolani et al. (1987), em um acompanhamento sorológico de bovinos adultos vacinados com a B19, constataram em seu estudo que 88,88\% dos animais vacinados após 120 dias apresentaram titulação negativa no grupo 1 e $50 \%$ no grupo 2. Pela prova do SAL no grupo 1, apresentou $50 \%$ de titulação negativa e $0 \%$ no grupo 2. Após 690 dias, o 2-ME não detectou nenhuma titulação no grupo 1 e apenas 12,5\% apresentaram titulação no grupo 2 . No SAL, 83,3\% não apresentaram titulação no grupo 1 e $25 \%$ no grupo 2.

\section{CONCLUSÕES}

- As provas preconizadas pelo Programa Nacional de Controle e Erradicação da Brucelose e Tuberculose Bovinas são testes de fácil padronização nos laboratórios, baixo custo e com boa dinâmica no que se refere à sensibilidade e especificidade;

- O AAT prevalece como um teste de triagem por ser rápido, de baixo custo e alta sensibilidade, quando comparado aos testes SAL e 2-ME; o valor encontrado no presente experimento foi de $100 \%$;

- O SAL demonstrou ser um teste com sensibilidade semelhante ao AAT, com percentual de 98\%;

- O SAL, quando comparado com 2-ME, apresentou sensibilidade de $100 \%$ e especificidade de $80 \%$, confirmando os dados da literatura que preconizam o SAL como um teste mais sensível comparado ao 2-ME;

- O 2-ME, por ser um teste confirmatório de eleição, apresenta boa especificidade e sensibilidade comparado ao SAL e AAT; observa-se uma sensibilidade de $89 \%$ e $88 \%$ para o SAL e o AAT, respectivamente. Contudo, a especificidade do 2-ME demonstrou superioridade em relação ao SAL, com percentual de 100\%, mostrando que o teste apresenta resultados seguros para o diagnóstico da brucelose bovina.

\section{REFERÊNCIAS}

ACYPRESTE, C. S. et al. Diagnóstico da freqüência da brucelose bovina em vacas em lactação na bacia leiteira de Goiânia pelas provas do anel do leite e rosa de bengala. Ciência Animal Brasileira, Goiânia, v. 3, n. 1, p. 59-65, 2002.

AGUIAR, D. M. et al. Soroaglutinação: sêmen plasma aglutinação e exame andrológico no diagnóstico da brucelose em machos bovinos. Arquivo do Instituto Biológico, São Paulo, v. 68, n. 2, p. 103-105, 2001.

JARDIM, G. C. et al. Diagnóstico sorológico da brucelose bovina em animais adultos vacinados com dose reduzida da cepa 19 de Brucella abortus. Pesquisa Veterinária Brasileira, Rio de Janeiro, v. 26, n. 3, p. 177-182, 2006.

KURODA, R. B. S. et al. Estudo comparativo dos resultados das técnicas de soroaglutinação lenta em tubos, 2-Mercaptoetanol e fixação de complemento. Arquivo do Instituto Biológico, São Paulo, v. 71, n. 2, p. 137-142, 2004. 
MADRUGA C. R.; ARAÚJO F. R.; SOARES C. O. Imunodiagnóstico em medicina veterinária. EMBRAPA Gado de Corte: Campo Grande, 2001, 360 p.

MATHIAS, L. A, et al. Evolução de títulos sorológicos, nas provas de soroaglutinação em placa, antígeno acidificado tamponado e fixação de complemento, em bezerras nelores vacinadas aos 18 meses de idade com Brucella abortus amostra B19. Pesquisa Veterinária Brasileira, Rio de Janeiro, v. 21, n. 4, p. 139142, 2001.

MEGID, J. et al. Avaliação das provas de soroaglutinação rápida, soroaglutinação lenta, antígeno acidificado tamponado e 2-mercaptoetanol no diagnóstico da brucelose bovina. Brazilian Journal of Veterinary Research and Animal Science, São Paulo, v. 37, n. 5, 2000.

MOLNAR, L. et al. Concepções modernas para o diagnóstico da brucelose. Revista Brasileira de Medicina Veterinária, São Paulo, v. 19, n. 4, p. 157-162, 1997.

ORTOLANI, E. L. et al. Acompanhamento sorológico de bovinos adultos vacinados com amostra B19. Teste de soroaglutinação lenta e 2-Mercaptoetanol. Arquivo Brasileiro de Medicina Veterinária e Zootecnia, Belo Horizonte, v. 39, n. 3, p. 377-386, 1987.

PAUlim, L. M. et al. Estudo Comparativo dos Testes 2-Mercaptoetanol e Reação de Fixação de Complemento no Sorodiagnóstico da Brucelose Bovina. Arquivo do Instituto Biológico, São Paulo, v. 69, n. 4. p. 41-47, 2002.

RADOSTITS, O. M.; GAY, C. C.; BLOOD, D. C. Veterinary Medicine. A textbook of the diseases of cattle, sheep, pigs, goats and horses. 9. ed. London: W.B. Saunders, 2000. p. 867-891.

RIBEIRO, M. G. et al. Perfil sorológico Anti-Brucella abortus em bezerras vacinadas com amostra B19. Arquivo Brasileiro de Medicina Veterinária e Zootecnia, Belo Horizonte, v. 49, n. 2, p. 137-150, 1997.

SALGADO, G. Estúdio de Brucellosis a partir de muestras de leche de bovinos en el trópicos subhúmidos del estado de Guerrero. Revista México, Ciudad Universitária, v. 26, n. 4, p. 359-363, 1995.

Recebido em: 09/10/2006

Received in: 10/09/2006

Aprovado em: 30/03/2007

Approved in: 03/30/2007 